ANUARIO DE Estudios MEDIEVALES 49/2, julio-diciembre de 2019, pp. 427-451

ISSN 0066-5061

https://doi.org/10.3989/aem.2019.49.2.02

\title{
AMAR EN TIEMPOS MONÁSTICOS: ESTRATEGIAS DE REPRESENTACIÓN EN EL INTERCAMBIO EPISTOLAR ENTRE BAUDRI DE BOURGUEIL Y CONSTANCIA DE LE RONCERAY*
}

\author{
LOVING IN MONASTIC TIMES: STRATEGIES OF REPRESENTATION IN \\ THE EPISTOLARY EXCHANGE BETWEEN BAUDRI OF BOURGUEIL AND \\ CONSTANCE OF LE RONCERAY
}

\author{
LaURa CAmino Plaza \\ Universidade de Santiago de Compostela \\ https://orcid.org/0000-0001-6869-8829
}

\begin{abstract}
Resumen: En este trabajo se contemplará qué tipo de dinámicas de construcción de identidad y de género se pueden extraer del intercambio de cartas elegíacas producido entre el que fue arzobispo de Dol, Baudri de Bourgueil, y la monja Constancia de Le Ronceray. El resultado del análisis revertirá en una propuesta interpretativa en la que se sugerirá entender dichas estrategias de representación como parte de las tensiones propias que los movimientos reformistas estaban causando en el tejido social y cultural de inicios del siglo XII.

Palabras clave: epístola; elegía; estudios de género; religiosidad; reformismo bajomedieval.

Abstract: This article examines what dynamics of identity and gender can be extracted from the exchange of elegiac letters between the archbishop of Dol, Baudri of Bourgueil, and the nun Constance of Le Ronceray. The results suggest that those strategies of representation were part of the tensions caused in the socio-cultural context of the early $12^{\text {th }}$ century by the reform movements. Keywords: epistle; elegy; gender studies; piety; late medieval reformism.
\end{abstract}

\section{SUMARIO}

1. Introducción.- 2. Baudri y Constancia como sujetos históricos.- 3. Baudri y Constancia como personae poéticas.- 4 . Conclusiones.- 5. Bibliografía citada.

\section{INTRODUCCIÓN ${ }^{1}$}

Existió en territorio francés un lugar en el que, a principios del siglo $\mathrm{XII}$, las monjas que lo habitaban empezaron a recibir cartas de hombres ansio-

\footnotetext{
* Esta investigación fue galardonada con el $2^{\circ}$ premio de la IX Edición de los Premios a la Introducción de la Perspectiva de Género en la Docencia y la Investigación de la Universidade de Santiago, en el año 2018.

${ }^{1}$ Abreviaturas utilizadas: c. = "carmen", poema (plural cc.); DMLBS = Dictionary of Medieval Latin from British Sources, edición online (http://www.dmlbs.ox.ac.uk); PL = Patrologia Latina, edición de J. Migne; TLL = Thesaurus Linguae Latinae, edición online (https://www. degruyter.com/view/db/tll).

Citation / Cómo citar este artículo: Camino Plaza, Laura (2019), Amar en tiempos monásticos: estrategias de representación en el intercambio epistolar entre Baudri de Bourgueil y Constancia de le Ronceray, "Anuario de Estudios Medievales" 49/2,pp. 427-451. https://doi.org/10.3989/aem.2019.49.2.02

Copyright: (C) 2019 CSIC. Este es un artículo de acceso abierto distribuido bajo los términos de la licencia de uso y distribución Creative Commons Reconocimiento 4.0 Internacional (CC BY 4.0).
} 
sos por leer las epístolas que ellas habrían de mandarles de vuelta ${ }^{2}$. Este sitio es la abadía de Le Ronceray ${ }^{3}$, en Angers, que había sido fundada el 14 de julio de 1028 por Hildegarda, esposa del conde de Anjou Fulco III, famoso por su crueldad pero también por su afán benefactor. Fulco no se había ganado en balde el apodo de "El Constructor" con el que pasaría a la posteridad (junto con el de "Halcón Negro", para ser justa, que apunta a su parte más oscura), ya que ciertamente le debemos la edificación de una serie de abadías e iglesias en esta misma época a lo largo y ancho de Anjou ${ }^{4}$. Pero la abadía que me ocupa ahora, la de Le Ronceray, es importante entre otras cosas porque es la única abadía de mujeres antes de la creación de Fontevraud, también en la misma zona ${ }^{5}$. Los registros muestran que acogía a mujeres aristocráticas, siendo la mayoría de estas monjas y jóvenes vírgenes. También vivieron allí mujeres viudas e incluso otras casadas ${ }^{6}$. Centro de referencia para las nobles cultas de Francia, Le Ronceray seguía los preceptos de la orden benedictina aunque las monjas que allí habitaban gozasen de más libertad than the Rule of Benedict called for ${ }^{7}$ y aunque no todas las mujeres que formaban parte de la comunidad estuviesen consagradas a la vida monástica ${ }^{8}$.

Las fuentes que todavía conservamos nos muestran que entre los siglos XI y XII las mujeres de este convento interactuaban with many neigh-

\footnotetext{
${ }^{2}$ Los fragmentos de obras literarias latinas que se presentan en este trabajo se aportan directamente en mi traducción al castellano, junto con las referencias al original oportunas. Dada la profusión de fragmentos usados en la argumentación, con esta decisión busco, por un lado, amenizar la lectura y, por otro, solventar los problemas de espacio que implicaría reproducir los textos en bilingüe.

${ }^{3} \mathrm{Su}$ iglesia se reconstruye sobre las ruinas de una más antigua, que se llamaba Notre Dame de la Charité. En 1527 tanto la abadía como la iglesia recibieron el nombre de Le Ronceray, que hoy usamos por convención. Véase Salies 1874,p. 195.

4 "Ce serait donc l'expression de la politique comtale de fondations religieuses qui aurait prévalu chez les Plantagenêts dans la première moitié du XIe siècle" (Avril 1983, p. 30).

${ }^{5}$ Peteul 2005, p. 3.

${ }^{6}$ Verdon 1976, pp. 248-252.

${ }^{7}$ Brower 2011, p. 76, n. 65. En la misma nota: "This is not to say that the nuns were under no restrictions. On the contrary, [Tuten] notes that whereas monks were free to manage monastic holdings outside the cloister themselves, nuns, even those at Le Ronceray, had to rely on lay officers because, while they technically had the option of leaving the cloister to visit these properties, "frequent or unaccompanied travel was not considered proper for religious women, and probably happened less often" (Tuten 1997, p. 44)".

El monográfico editado por Hamburguer y Marti (2008) aborda el estudio del monacato femenino de manera diacrónica, multiterritorial e interdisciplinar, aportando referencias sobre el caso benedictino.

${ }^{8}$ Tyler establece un paralelismo entre el convento de Le Ronceray en Francia y el de Wilton en Inglaterra (con el que por cierto Baudri también mantuvo una relación; véase nota 21), en términos que destacan la "apertura al mundo" de la que ambos lugares hacían gala: "Le Ronceray, with its aristocratic lay and secular women, its reputation for scholarship, and its close ties to the local aristocracy and clergy, recalls the openess and worldiness of Wilton" (Tyler 2017, p. 243).
} 
bors, both lay and monastic ${ }^{9}$, contra los que muchas veces tuvieron que enfrentarse para proteger sus propiedades y derechos ${ }^{10}$, lo que sin duda podría ser interesante también para los medievalistas que apliquen en sus trabajos las herramientas y métodos propios de la historia económica y/o judicial. Este estudio centrará en cambio su enfoque en el desdoblamiento literario que dos sujetos históricos que estuvieron ligados a Le Ronceray (Baudri y Constancia) hacen de sí mismos y de sus respectivas identidades a través de un intercambio de cartas poéticas ${ }^{11}$ en el que han construido sus personae literarias sobre dos tipos de tensiones principales: la que se da entre la tradición e innovación literarias, y la que se produce entre las diferentes maneras de sentir el mundo y vivir las relaciones interpersonales que esa tensión primera lleva pareja al comportamiento de cada sexo en un momento histórico determinado y concreto como es el inicio del siglo XII en la Francia central. Ya que el análisis de este intercambio elegíaco-epistolar pondrá de relieve ciertas dinámicas de construcción de identidad y de género dentro de un marco más general en el que se observará el papel de la mujer como sujeto histórico participante de los acontecimientos de la época, cabe mencionar que este trabajo no pretende asentar una idea fija, estanca y única de cómo se habrían relacionado los hombres y mujeres de aquel momento, ni tan siquiera de cómo se habrían (auto)definido ${ }^{12}$. Con todo, aceptar que en el medievo existió una pluralidad de formas y maneras con las que expresar estas estrategias no impide la posibilidad de extraer ciertas conclusiones a través del análisis de los textos que aquí presento.

El primer apartado de este trabajo estará dedicado a situar históricamente a nuestros dos protagonistas. Para ello explicaré su relación con Le Ronceray y defenderé la existencia de una comunidad de mujeres lectoras y escritoras en el convento a inicios del siglo XII. En la siguiente sección seguiré apoyándome en testimonios literarios para dar cuenta de que en el intercambio mantenido entre Baudri y Constancia encontramos rastros de un amor

9 Tuten 1997, p. 10. Estas mantuvieron otros contactos, ya que "the comparative freedom with which Ronceray nuns moved about the city further permitted them to maintain ties with their families and form additional social connections" (ibidem, p. 44).

${ }^{10}$ Ibidem, p. 3.

${ }^{11} \mathrm{El}$ intercambio epistolar en el que este estudio se centra se compone de dos cartas escritas en versos elegíacos, recogidas por el editor de Baudri, Jean Yves Tilliette, bajo los números 200 y 201 de la colección. La carta-poema 200 es la que Baudri envía a Constancia, la otra es la respuesta de ella. Todos los poemas baudrinianos presentes en este estudio se han recogido de la edición en dos volúmenes de Tilliette 2002 y 2012, a la que remito para consultar el texto latino.

${ }^{12}$ Soy deudora de las teorías que consideran que no hay una concepción unívoca del género, sino que esta es una construcción mutante y mutable tanto desde un punto de vista sincrónico como diacrónico, atravesada por discursos y comportamientos culturalmente afectados. Véase Butler 1998 para una formulación y revisión de estas ideas. 
que fluctúa entre el erotismo y la castidad, entre la obediencia de la mujer y su reconocimiento como igual. Por último, plantearé que las ambigüedades y tensiones presentes en los textos pueden ser reflejo del complejo contexto socio-cultural de inicios de aquel siglo, afectado por la actuación del reformismo y por la inclusión de la mujer en un tipo concreto de discurso público.

\section{BAUDRI Y CONSTANCIA COMO SUJETOS HISTÓRICOS}

El último de los editores de Baudri de Bourgueil, Jean Yves Tilliette, explica en la introducción a los Carmina o poemas de aquel que, en el único manuscrito que conservamos (y que hoy se encuentra en el Vaticano, Bibl. Apost. Vat., Reg. Lat. 1351), un bibliotecario del XVIII reconocía la autoría de Baldrici abbatis Burguliensis in Andegauis postea episcopi Dolensis carmina ${ }^{13}$. Esos son los principales cargos religiosos que le seguimos reconociendo hoy en día al poeta Baudri: haber sido abad del monasterio benedictino de Saint-Pierre-de-Bourgueil entre $\mathrm{ca} .1080^{14}$ y $1107 \mathrm{y}$, desde ese momento hasta su muerte (acaecida en 1130, a la edad de 84 años), haber estado al frente del arzobispado de Dol-de-Bretagne.

Entre ambos cargos, el escándalo: en el año 1096 se le acusó de simonía al intentar comprar la sede episcopal de Orleans con la ayuda de Bertrarda de Montfort, quien estaba casada en segundas nupcias con Felipe I, rey de Francia entre 1060 y 1108. Este enlace trajo polémica consigo, ya que para que llegase a suceder Felipe I tuvo que repudiar antes a la que era su esposa, Berta de Holanda, y luego secuestrar a Bertrarda de Montfort y alejarla de su marido, Fulco IV "El Rico". El rey fue excomulgado por el Papa Urbano II en octubre de 1094, lo que se confirmó en el Concilio de Clermonte en noviembre del año siguiente, aunque el matrimonio acabaría siendo finalmente aceptado como válido tras el Concilio de París (1104). Que en medio de esta peliaguda situación, Baudri hubiese hecho tratos con Bertrarda para comprar un cargo religioso, algo que ya había sido prohibido desde el sínodo en Letrán que el papa Nicolás II había convocado en 1059, era algo que los seguidores de la reforma gregoriana no podían aprobar, como muestra el enfado con el que su contemporáneo el obispo Ivo de Chartres relató el episodio en su co-

\footnotetext{
${ }^{13}$ Tilliette 2012, p. VI, n. 2.

${ }^{14}$ Pasquier 1878,p. 274, indica que Baudri habría sido prior y luego abad de Bourgueil. Para la asunción de este último cargo, acepta la fecha de 1089 como válida, fiándose de los datos proporcionados por Fouquet en L'Histoire manuscrite française de Bourgueil (citado en Pasquier 1878, p. 274, n. 3). Guillot (1972, vol. 2, p. 212) rechaza en cambio la veracidad de esas fuentes y considera que Baudri tuvo que haber accedido al cargo entre 1078 y 1082.
} 
rrespondencia ${ }^{15}$. Tilliette considera, de todos modos, que el tipo de prácticas que el movimiento reformista condenaba seguían siendo en realidad bastante frecuentes en época de Baudri ${ }^{16}$. En su opinión, lo que demuestra el enfado de Ivo de Chartres es que el mundo eclesiástico empieza a indignarse ante ellas, no que efectivamente no fuesen más la regla que la excepción ${ }^{17}$. Sea como fuere, Baudri consiguió el perdón y el arzobispado de Dol le fue concedido, aunque a juzgar por sus testimonios, no le gustaba nada vivir entre bretones, a quienes consideraba incultos ${ }^{18}$. El resto de su vida habría transcurrido tranquila, a excepción de la suspensión que, por legado papal, sufrió en 1120 al ser acusado de prebenda. Sería en esta parte final de su existencia cuando habría realizado sus viajes a monasterios benedictinos de Inglaterra (Worcester) y Normandía (Fécamp, Bec), junto con los que además le llevaron a Roma ${ }^{19}$.

Pero sobre todas las cosas, Baudri de Bourgueil fue un hombre de letras, que se consideraba a sí mismo poeta, pese a haber cultivado también otros géneros como prosa hagiográfica, histórica, vitae... Hoy en día se le encuadra dentro de la llamada "Escuela del Loira", paraguas bajo el cual la crítica intenta aglutinar las similitudes que existen entre su obra y la de sus coétaneos Hildeberto de Lavardin y Marbodo de Rennes, también hombres de vida religiosa. Escribió su poesía durante la época de su abaciato ${ }^{20}$, cuando aún vivía en Bourgueil, que pertenecía a la diócesis de Angers y formaba parte del condado de Anjou. De los 256 poemas que componen su libro, muchos fueron además epístolas y, aunque la gran mayoría las dirigió a hombres, también hubo un grupo de mujeres de la misma diócesis y condado que fueron receptoras privilegiadas de las cartas poéticas de nuestro autor: las monjas de Le Ronceray ${ }^{21}$. En honor a la verdad, no fueron solo las "amigas por

\footnotetext{
${ }^{15}$ Véase su carta 65, recogida por Leclercq 1949, pp. 282-291, esp. p. 288. En el sínodo de 1059 también se reformó el sistema de elección papal, sustrayéndole poderes al emperador y, lo que es más importante para mi argumentación, se empezó a perseguir también el matrimonio de los clérigos.

${ }^{16}$ Tilliette 2012, p. VIII.

${ }^{17}$ Alberto González, en su estudio sobre la Garcineida, una sátira de finales del XI en la que se crítica la corrupción de la Curia Pontificia durante el mandato del papa Urbano II (es decir, entre 1088-1099), ha demostrado que, aunque los ataques a la corrupción eclesiástica son muy comunes en la literatura de mitad del s. XII en adelante (González 2013, p. 627), pueden encontrarse ya en la del siglo anterior, lo que sin duda va en la misma línea que la carta que mencionamos de Ivo de Chartres. Corroborando la afirmación de Tilliette según la cual las prácticas simoníacas eran habituales en este período, González (ibidem, pp. 620-625) elabora un listado con ejemplos de las mismas.

${ }^{18}$ Itinerarium, PL, 166, $1173 \mathrm{c}$.

${ }^{19}$ Pasquier 1878 , pp. 285 y 289.

${ }^{20}$ Tilliette 1983, p. 243.

${ }^{21}$ De Baudri recibieron también cartas poéticas Cecilia, abadesa de Caén e hija de Guillermo I el Conquistador, y Muriel, monja y afamada poeta del convento de Wilton en Inglaterra. De
} 
correspondencia" de Baudri, sino también las amicae y puellae anónimas a las que mandó efusivos poemas Marbodo de Rennes y también las destinatarias de las poesías de Hilario, canónigo del propio convento de Le Ronceray ${ }^{22}$.

La popularidad de estas mujeres ha llamado la atención de historiadores y filólogos. Belle Tuten pertenece precisamente al primer grupo y ha centrado su labor investigadora en estudiar las actas y registros que se conservan de Le Ronceray para conseguir desentrañar la identidad de estas mujeres ${ }^{23}$. Así, ha conseguido demostrar que la mayoría de las actas que mencionan a las destinatarias de Baudri pertenecen al período en el que Tiburga fue abadesa, es decir, entre 1104 y 1122, por lo que supone que esta mujer habría promovido la actividad intelectual del convento ${ }^{24}$. Las monjas de Le Ronceray a las que Baudri de Bourgueil escribe son Agnes ${ }^{25}$, la maestra de gramática Emma ${ }^{26}$, la novicia Beatriz ${ }^{27}$ y por supuesto, nuestra Constancia ${ }^{28}$. Menos Agnes que recibió una, las restantes mujeres contaron con dos cartas en verso de nuestro autor. La muerte de Constancia es lamentada en otro poema de Baudri ${ }^{29}$, lo que puede ayudarnos a establecer un término ante quem en el que situarla cronológicamente, ya que como dijimos la colección habría sido escrita durante el abaciato del poeta, cargo que recordemos dejó en el 1107.

El primer poema que Baudri manda a Constancia, de 52 versos, carece del tono lúdico y ambiguamente amoroso del segundo, que es el que

entre las mujeres de la nobleza laica de la época, la condesa Adela de Blois fue la destinataria de dos poemas de Baudri, uno de ellos de gran extensión. La conexión entre Wilton y Le Ronceray la estudia Tyler 2017, pp. 242-259.

${ }^{22}$ Los poemas de Marbodo fueron recopilados por Bulst 1950; los de Hilario los editó por primera vez Champollion en 1838.

${ }^{23}$ Véase Tuten 2004. En este trabajo dice basarse en la edición de las actas de Le Ronceray llevada a cabo por Paul Marchegay (1854), a la que se refiere como R y que está digitalizada por la Bibliothèque Nationale de France. Sin embargo, hay que prestar atención a que los datos dados por Tuten no coinciden en ocasiones con los de Marchegay. Solo revisando otro trabajo suyo (Tuten 1997, p. 32, n. 57), he podido comprender que lo que hace Tuten es completar y reorganizar las actas editadas por Marchegay, comparándolas con el manuscrito original que se encuentra en la Bibliothèque Municipale d'Angers (mss. 844-848). En el presente trabajo sigo la enumeración de Tuten.

${ }^{24}$ Según recoge Marchegay 1876, p. 247, Hilario le pedirá a Tiburga que responda a sus poemas con más poemas: "Adiós, dulce señora, y a mis poemas responde con poemas, y envíame dádivas junto con tus versos". Esta petición corroboraría que en este siglo no era extraño que hombres y mujeres se carteasen y parece indicar, de nuevo, que Tiburga habría estado implicada en el desarrollo literario de Le Ronceray.

${ }^{25}$ Tuten cree que esta Agnes podría ser la sobrina de Orielda, a quien Baudri menciona en el poema 139 dirigido a Emma y que aparece en R 387 (1125). Otra posibilidad es que fuese Agnes de Craon, atestiguada en R 77 (1116).

${ }^{26} \mathrm{R} 446$ (1118).

${ }^{27} \mathrm{R} 124$ (1126), 208 (1115), 383 (1125), 308 (1130), 333 (i), 416 (1132), 426 (1128).

${ }^{28} \mathrm{R} 192$ (1129), 247 (1110).

${ }^{29}$ c. 213. 
provoca la respuesta de la monja; ambos serán analizados conjuntamente en el siguiente apartado. En esta primera misiva a nuestra monja, en cambio, Baudri centra sus esfuerzos en exhortarla a mantener su virginidad y el respeto por su esposo, Cristo, quien solo se complace cuando la castidad va acompañada de una integridad también moral: La integridad de la carne sin la integridad del espíritu / para nada es una víctima grata a Dios (c. 142, vv. 21-22).

De esta primera carta poética me interesa especialmente el final (vv. 45-52), en el que Baudri la invita a que le responda con dulces discursos al tiempo que le pide que salude a Emma tres o cuatro veces:

Te pido, además, que no te olvides de mí, haz que tu corazón y tu hígado me tengan en un lugar especial.

Si quieres mandarme algo, confiáselo a las tablillas: este género de envío me conviene, por tanto, me place.

Con tus dulces discursos suaviza las entrañas del padre, y muéstrame amabilidad con tus dulces discursos.

Además, no me olvido de nuestra Emma, preséntale mi saludo tres o cuatro veces.

Así, esta parte nos corrobora que existió una relación entre Constancia y Emma, la maestra de gramática según los registros de la época. Lo más lógico es pensar que esta última estaba a cargo de la educación de las mujeres de Le Ronceray, lo que nos confirma de hecho Baudri en el poema 139 (vv. 7-16) de la colección, donde deja claro que Emma tenía un grupo de felices alumnas bajo su tutela:

Hace un tiempo me eras conocida solamente por tu fama o conocida, apenas, por encuentros públicos;

ahora vives en mí, no como una joven compañera de rebaño sino como una muchacha de renombre en el rebaño que la sabiduría mantuvo caliente con su propia miel para que ahora tus pechos emanen su leche.

Esto se me reveló recientemente al leer tus poemas, los que tú gratuitamente habías condimentado con néctar.

Hacia ti corren los enjambres de alumnas

para que las abejas revivan con la miel de la abeja madre.

El pasaje, como vemos, da cuenta también de la capacidad de Emma para escribir buena poesía, merecedora de respeto y fama. Si en el poema anterior observábamos cómo Baudri le pedía a Constancia que le escribiese de vuelta con dulces discursos, los restantes testimonios que conservamos dirigidos a las monjas de Le Ronceray nos hacen pensar que efectivamente parece haber existido una comunidad de mujeres escritoras y lectoras a inicios del siglo XII en la ciudad de Angers. En el poema 138 a Agnes, Baudri recurre a 
una estructura que ya nos es familiar: tras animar a la monja a que siga siendo casta, le pide que se centre en el estudio y la escritura y para terminar le solicita que le escriba una respuesta en verso ${ }^{30}$. Por su parte, en el primero de los dos poemas a Beatriz, nuestro autor ataca a esta mujer por no ceder a sus ruegos, que no son otros que los de recibir sus poesías:

Le pedía a menudo que recitase sus poemas o los míos -no le faltaban poemas ni de estos ni de aquellospero taciturna en exceso, puso un dedo sobre la boca y tras desplegar su velo, como que se ocultó; (...) (c. 140, vv. 5-8).

El segundo (c. 141), de solo cuatro versos, es de nuevo una queja motivada por la misma razón: el silencio de la muchacha:

La montaña dio a luz a un ratón ${ }^{31}$, porque Beatriz la muda, habla;

ha escrito, ha compuesto, pero casi nada ha hablado.

$\mathrm{O}$ nada es lo que dice, o lo que escribió lo proteja

Y su poesía defienda con poesía.

Importantísima es la carta en verso número 153 a Emma, en la que le pide que corrija su libro, es decir, la colección de poemas que es objeto de este estudio. Así, los versos 9-12 y 23-24:

Pero ahora te confío mi pequeño libro en su totalidad para que lo leas, aplicada, lo veas con cuidado extremo.

Utiliza la forma de un crítico, no el amor del jugador, no toquetees lo que se debe quitar.

$$
(\ldots)
$$

Con la boca de la Sibila que responda Emma a lo que pido, que lea con cuidado, que quite, que corrija, que añada (...).

Baudri invitará también a las demás monjas a que participen de la lectura de su libro y del debate posterior, lo que en mi opinión refuerza su imagen como una comunidad de mujeres educadas y con inquietudes literarias:

\footnotetext{
${ }^{30}$ c. 138, vv. 23-24: "Por eso, conserva la virginidad que te hace fuerte, / que si la perdieses, dejarías de ser quien eres"; luego, v. 32: "Reza, escribe, lee y ocúpate con la poesía" y, por último, vv. 37-38: "Mientras tanto te envío de mi parte un saludo / y tú también envíame el tuyo en verso".

31 "La montaña dio a luz a un ratón" o "Murem mons peperit", está haciendo referencia a Ars Poetica, 139 ("Parturient montes, nascetur ridiculus mus"), donde Horacio se burla de aquellos poetas que prometen demasiado y luego no pueden cumplir las expectativas.
} 
A las hermanas que quieras y cuantas quieras, que se reúnan un día, pero que no vaya la ignorante o locuaz.

El charloteo y la lengua resuelta y el espíritu maligno

lanzan un hechizo sobre las inocentes, y daña el debate.

Entre los filósofos valía mucho la comparación, así tú debate y también sola lee mucho.

(c. 153, vv. 17-22).

Este dato es relevante también para el intercambio entre Baudri y Constancia que pasamos a analizar seguidamente, ya que uno de los motivos que la crítica ha aducido para considerar que la carta de Constancia no sería de su autoría, sino que la habría escrito Baudri como ejercicio retórico-literario, es que en la réplica de ella hay referencias a otras partes del libro de poemas de él y también a otras obras de autores clásicos. Mientras que hay quien ve en lo primero un indicio más para pensar que el libro de Baudri habría sido leído, debatido y comentado en su totalidad por Emma y las demás mujeres de Le Ronceray (tal y como el poeta le pedía a la maestra), las referencias a otras obras clásicas que aparecen en el poema 201 son usadas por otros investigadores para dudar de la autoría de Constancia en base a una supuesta falta de educación literaria (o al menos, de testimonio de esa educación) en los conventos franceses de la época ${ }^{32}$. Tristemente, los inventarios contemporáneos que dan cuenta de qué libros estarían recogidos en las bibliotecas benedicitinas francesas de los siglos XI y XII son una source bien lacunaire, pues pese a que sabemos que este había sido un momento de auge para los monasterios y sus bibliotecas, han llegado en cambio muy pocos de estos catálogos hasta nuestros días ${ }^{33}$. Tomar esta ausencia de fuentes como una prueba de la pobreza o falta de cultura literaria de estas mujeres, más aun cuando tenemos testimonios como los que se han venido aduciendo que demuestran la estima que estas monjas despertaban en calidad de mujeres sabias, ávidas lectoras y escritoras, parece ciertamente desatinado ${ }^{34}$.

\footnotetext{
${ }^{32}$ Así Brower 2011, p. 108 y Tillette 1992, p. 142, respectivamente, son ejemplos de estas tendencias opuestas.

${ }^{33}$ Munk Olsen 1989, p. 32, nos cuenta que conservamos 46 inventarios propiamente dichos para la Francia y Bélgica de entre mediados del XI e inicios del XIII. Ninguno, lamentablemente, de Le Ronceray, convento que habría apoyado incluso una escuela externa para hombres, lo que fortalecería la hipótesis de que fue un centro con vocación educativa (Tyler 2017, p. 243).

${ }^{34}$ Para otros trabajos que defienden la educación de las monjas medievales a través de testimonios literarios véase la monografía editada por Blanton et al., especialmente el capítulo de Weston 2013. Véase también Beach 2002 y 2004.
} 


\section{BAUDRI Y CONSTANCIA COMO PERSONAE POÉTICAS}

Acabamos de ver cómo Baudri escribió una primera carta en verso a Constancia, de extensión no muy larga, exhortándola a vivir de manera casta y honesta, en la que al final también se acordaba de saludar a Emma. También he mencionado ya que nuestra monja será la destinataria de una segunda carta-poema, más larga ${ }^{35}$ y más interesante para mi análisis, de tono ambiguamente amoroso, algo que como quiero explicar ahora queda manifiesto desde el inicio de la propia misiva. Así, aunque Baudri le confiese a Constancia que a lo que resuena su epístola es a amor, pues efectivamente es un poema de amor (c. 200, v. 7), a continuación tiene que dejarle claro que puede leer la carta tranquila, ya que en ella no se esconde ningún veneno (c. 200, v. 8). Estas tensiones entre lo que parece un poema de amor a una mujer maravillosa, pero que en realidad es un poema casto a la esposa de su $\operatorname{Señor}^{36}$, se resumen en una elocuente sentencia: sea el pudor en el acto, sea el juego en la pluma (c. 200, v. 46) $)^{37}$. Al conflicto entre un amor casto que puede ser otra cosa pero que no es (propiciado por supuesto por la capacidad de la literatura para crear distintas identidades y otros mundos posibles), le acompaña una tensión entre la tradición y la innovación literarias, actualizada como una negociación entre el paganismo y el cristianismo. Baudri, lector de Ovidio ${ }^{38}$, poeta del amor por excelencia en la antigua Roma ${ }^{39}$, escribe a Constancia un poema de amor en

${ }^{35}$ Se trata de un poema compuesto de 89 dísticos elegíacos o, lo que es lo mismo, 178 versos.

${ }^{36}$ Así, en los vv. 15-18 Baudri le dice a Constancia: "¡Oh, si al menos supieras, como mi corazón sabe, cuánto significas para mí, cuán mía te hago / Para mí vales más y eres mejor, y vives en mí más grande / que una diosa, que la Virgen o que cualquier objeto de amor". Sin embargo, más adelante, en los vv. 137-140, tenemos la siguiente confesión: "Que seas, esposa de mi Señor, un palacio de un esposo tan grande, / que de tal esposo seas esposa y lecho. / Destruya el Señor a quien destruya su templo, / a quien, piedra él mismo, mata a las piedras vivientes".

${ }^{37}$ Véase Bond 1986 para la importancia del juego en la obra de Baudri.

${ }^{38}$ En el c. 111 se lamenta por haber dejado "un Ovidio" a alguien que no sabe si se lo devolverá. Sobre la importancia de Ovidio y, especialmente de Heroidas, en la obra de Baudri, véase Bond 1986 y 1987. Que Baudri se haya carteado con Constancia a la manera de las Heroidas dobles habría supuesto el último eslabón de este poeta en la inserción de su propia persona en el marco ovidiano (Bond 1987, p. 104; Brower 2011,p. 15).

Por otro lado, cabe destacar que la relación entre la poesía amorosa de Ovidio y la de Baudri, más la conexión entre ambas poéticas con el código del "fin'amor" cortés, ya ha sido apuntada por otros investigadores. Brinkmann (1971, pp. 13-61) sugiere que el círculo poético del Loira actúa de intermediario entre el código amoroso de Ovidio y el de los primeros trovadores. Bond (1986, p. 144, n. 3) apunta a una conexión temática entre la obra de Baudri y la de Guillermo IX de Aquitania, considerado el primer trovador, cuyos primeros poemas se pueden datar en torno al 1105-1106.

${ }^{39}$ Así en Fastos IV, 8 Ovidio le reconoce a Venus, diosa del amor, ser su eterno seguidor ("tú siempre has sido mi propósito, tú siempre mi obra"). Barchiesi (1994, pp. 13-49) considera a Ovidio un poeta del amor, antibelicista y antiépico, y resalta las diferencias con Virgilio y la participación de este en el programa augusteo. 
forma de elegía; había sido este el género propio de la poesía amorosa entre los romanos y el que Ovidio había cultivado con más gusto. El propio Baudri matirazá la carga erótica de su misiva al cristianizar el sentido de su amor y ubicar el conflicto consiguiente dentro del mundo ficcional que le dispensa la pluma. Avanzada la carta, será el poeta quien dé a Constancia y, por ende, a todos los lectores, la clave hermenéutica con la que entender las tensiones de las que vengo hablando: si en su epístola hay ecos a la literatura pagana (leamos Ovidio, leamos erotismo) es para precisamente enseñarle de qué debe alejarse:

$$
\begin{gathered}
\text { Una virgen en flor enseñe sus floridas costumbres } \\
\text { y más que fuera, florezca en su interior. } \\
\text { La literatura de los gentiles tiene cabida en mi verso } \\
\text { para alejarte de la gente falsa } \\
\text { para que para tí sea gentil una gente y vil una literatura } \\
\text { que rinde culto a dioses impuros y semi-machos } \\
\text { que han cultivado más los burdeles } \\
\text { de lo que han puesto atención a las cosas de honestidad. } \\
\text { (c. } 200, \text { vv. 87-94). }
\end{gathered}
$$

Constancia entenderá el juego y, básicamente, replicará con un poema de la misma extensión que el de Baudri imitando los lamentos de las heroínas ovidianas. Así, empezará quejándose por la ausencia del amado ${ }^{40}$, continuará enfatizando su soledad y deseo de verlo ${ }^{41}$, le seguirán los celos ${ }^{42}$ y los reproches ${ }^{43} \mathrm{y}$, por último, acabará su carta con peticiones desesperadas para que vaya a verla ${ }^{44}$. Su epístola tendrá que hacer frente a las mismas tensiones que las vistas en la de Baudri, y de nuevo la escritura se convertirá en un aliado al que confiar la ficción libertadora. Gracias a ella, Constancia

${ }^{40}$ c. 201, vv. 57-60: ¡Oh, qué gran hombre, extraordinario hombre, se me muestra por su poema! Lo veo a través de sus versos, de hecho, no puedo hacer otra cosa. Pobre de mí, que no pueda ver con frecuencia a quien amo, / miserable, no puedo ver al objeto de mi deseo!"

${ }^{41}$ c. 201, vv. 79-81 “¿Pero qué hago? A nada lleva lo que desenrollo toda la noche / a nada, lo que ruego con mi pecho agitado: / no vendrá a mí ni lo veré saciar mi sed”.

${ }^{42}$ c. 201, vv. 87-88: "Ay, ¿qué no temeré? Nunca descansaré tranquila; / No estoy segura de su amor, ni estoy segura de su lealtad". También los vv. 93-98: "Ciertamente, no habría muchacha más afortunada que yo, / si estuviese segura de su amor y segura de sus promesas. / Aunque una fuerte lealtad confirme que es nuestro amigo, / no puedo creer con toda seguridad en su honestidad, / y no es que no crea en su fidelidad (ahí no hay nada que temer), / Pero temo perder lo que vehementemente amo".

${ }^{43}$ c. 201, vv. 169-170: "No te preocupas por mí si no has venido a mí, / ni siquiera un templado amor mueve tus vísceras".

${ }^{44}$ c. 201, vv. 173-178: "Debes verme, ignoras la enfermedad con la que languidezco, / el deseo que por supuesto me afecta. / Tu crimen es grande si no alimentas a la hambrienta, / si tú mismo no satisfaces a la que suplica. / Ven, eres esperado, y no quieras retrasar el día. / A menudo te he llamado; tú has sido llamado a menudo, ven". 
podrá escribirle a su amado muchas cosas que, por pudor, no podría decirle en persona ${ }^{45}$.

Por otro lado, a la carta de Constancia se le añade otro conflicto que no afecta a la de Baudri, y que no es otro que el de la mirada crítica posterior de quienes consideran que una mujer no habría podido escribir una carta poética de esas características en ese tiempo y en ese contexto dado ${ }^{46}$. Como ya anuncié al final del apartado anterior, la cuestión de la autoría de la carta de Constancia ha sido motivo de debate durante mucho tiempo y me temo que lo seguirá siendo. Mi intención en este trabajo dista mucho de intentar dar una respuesta a ese problema, sino que más bien pretendo mostrar que su carta refleja una serie de interesantes estrategias de representación, lo que en combinación con la epístola de Baudri nos ayuda a entender mejor cuál era la posición de la mujer en esa época ${ }^{47}$.

En un trabajo de lectura indispensable, Joan W. Scott discutía la necesidad de estudiar la Historia desde la categoría género porque gender is a constitutive element of social relationships based on perceived differences between the sexes, and gender is a primary way of signifiying relationships of power ${ }^{48}$. Cuando estas relaciones (sociales, de poder) empiezan a cambiar, también lo hace el imaginario, nuestro repertorio de símbolos y metáforas. Y así se van creando tensiones, como varias veces he mencionado ya en este artículo, fracturas, ambigüedades...pero también silencios. Ya nos los advertía Scott: cuando se trata de hacer historia en un mundo como el nuestro, repleto de oposiciones binarias (en este caso, hombre vs. mujer, masculino $v s$. femenino), además de desoírse otras posibilidades alternativas también se acaba construyendo la historia as if these normative positions were the product of social consensus rather than of conflict ${ }^{49}$. Ciertamente, si hablamos de la imagen de la mujer entre los siglos XI y XII estaremos moviéndonos en un terreno de conflicto más que de acuerdo del que es buen testigo la literatura.

\footnotetext{
${ }^{45}$ c. 201, vv. 105-106: "Le escribiré muchas cosas que no podría decir en persona: / la iniciativa de las muchachas a menudo la reprime el pudor".

${ }^{46}$ Cabe destacar que la colección baudriniana contiene también otro poema (c. 204) que no fue escrito por Baudri, sino por un hombre llamado Odo.

${ }^{47}$ Que un autor masculino hubiese dado voz a un personaje femenino tendría de todos modos repercusiones más allá de la mera retórica, afectando al campo de la teoría y de la política según Harvey (1995, p. 12), quien acuñó el término "transvestite ventriloquism" para precisamente poder hablar con propiedad de un fenómeno como este (aunque aplicado a textos del Renacimiento) en el que se acentúan "the issues of gender, voice, and authorial property" (Harvey 1995 , p. 1). En este trabajo hablaré de la carta de Constancia como si efectivamente la hubiese escrito ella para evitar mayores complicaciones, dado que lo que a mí me interesa no es la veracidad, sino la verosimilitud de este intercambio.

${ }^{48}$ Scott 1999, p. 66.

${ }^{49}$ Ibidem.
} 
Esta nos muestra que la misoginia podía ser una voz predominante en la Edad Media, pero desde luego no la única posible ${ }^{50}$. Incluso los mismos autores podían tener posiciones contradictorias (también complementarias) acerca de sus compañeras féminas ${ }^{51}$.

Farmer reconoció estas tensiones y supo ver que junto al discurso negativo sobre la mujer, durante los siglos XI y XII both scholastic and monastic authors began to recognize the moral and spiritual potential of women's persuasion ${ }^{52}$. Así se explica que en medio del contexto social y cultural misógino dominante hubiese efectivamente espacio para una visión positiva de la mujer, quien debía ser defensora de la moral cristiana y "suavizar el corazón de los hombres" ${ }^{53}$ que estuviesen tentados de actuar contrariamente a ésta. Aunque el estudio que hace Farmer de esta imagen doble de la mujer está centrado en el caso de las mujeres y esposas nobles (quienes por razones obvias tendrían más influencia en la vida social, económica y cultural de sus respectivos entornos), quiero apuntar aquí que observo también un paralelo con el tratamiento que reciben las mujeres de la vida monástica. Así, si las mujeres nobles han de enseñar a sus maridos el camino correcto ${ }^{54}$, las mujeres religiosas han de recordárselo a sus hermanas y suavizar los corazones de sus hermanos y padres cuando sea necesario ${ }^{55}$. Por así decirlo, deben recanalizar su poder seductor y persuasivo, ese que por otro lado las puede hacer tan peligrosas (para los hombres), hacia el bien, hacia la colaboración mutua en una vida casta y sacrificada.

La posibilidad de que la mujer falle, caiga en la tentación y se desvíe de la vida religiosa está presente en la literatura epistolar escrita por hombres en este período, y es precisamente esta misma posibilidad de la que se deriva la concepción de la mujer como sexo débil. En consiguiente, las exhortacio-

\footnotetext{
${ }^{50}$ Véase el necesario estudio de Murray 1995.

${ }^{51}$ Un caso cercano es el de Marbodo de Rennes, poeta del Loira que como ya vimos escribía cartas amorosas a las monjas de Le Ronceray, pero que también fue autor del Liber decem capitulorum, cuyo capítulo III está dedicado a la "muliere mala" y el IV a la "muliere bona".

${ }^{52}$ Farmer 1986, p. 521.

${ }_{53}^{53}$ Me permito parafrasear el título de otro trabajo de Farmer (1987).

${ }^{54}$ Como no podía ser de otra manera, en muchas ocasiones este camino pasa por favorecer a la Iglesia y establecer relaciones de mecenazgo y protección con sus líderes espirituales. Otras veces, esas mismas mujeres influyentes debían ayudar a rebajar, o incluso detener, ciertos conflictos históricos de su época, en muchos de los cuales por supuesto la Iglesia también tomaba parte. Algunos estudios sobre este tipo de conexiones y el papel de las mujeres nobles a las que escriben los poetas de la escuela del Loira y sus allegados son los de LoPrete 1992, 2007 y Huneycutt 1996.

${ }^{55}$ Así lo vimos en el primer poema de Baudri a Constancia: "suaviza las entrañas del padre con tus discursos dulces, / y muéstrame amabilidad con tus dulces discursos". Un ejemplo secular puede ser el de Ermengarda de Anjou convenciendo "con el más dulce de los discursos" a su marido, el conde Odo II, de reconstruir la iglesia de Epernay. Véase Farmer 1986, p. 524.
} 
nes masculinas a la castidad de las que son objeto estas mujeres encuentran legitimación en la propia naturaleza de ellas. La asociación de la mujer con los sentimientos y del hombre con la inteligencia, o lo que es lo mismo, la dicotomía pasión-razón, hunde sus raíces en la filosofía antigua y adquiere plena formulación con el cristianismo ${ }^{56}$. Como explica Marie-Thérèse d'Alverny, si en el s. I d. C. Filón de Alejandría ya elaboraba comentarios al Genésis en esta línea, San Ambrosio los recogerá y perpetuará en el s. IV con su sentencia la mujer es símbolo del sentimiento; el hombre, de la mente ${ }^{57}$. Aunque durante la Edad Media los hombres y mujeres hayan compartido (al menos teóricamente) una igualdad espiritual, la fricción entre sexos siempre ha estado presente, salpicada by negative images of woman as frail, seductive, and an impediment to man's salvation y perpetuando una oposición masculino / femenino que has been closely allied with the mind / body opposition ${ }^{58}$.

A este respecto, es destacable ver cómo Baudri y Constancia usan diferentes estrategias referenciales a la hora de describir al otro. Así, mientras que Baudri dedica solo 4 versos a elogiar la elocuencia de Constancia (c. 200, vv. 51-54), de los versos 55 al 64 describirá progresivamente la belleza de su cara (su cabello, su cuello, sus dientes, labios y mejillas), que está en harmonía con la del resto de su cuerpo, capaz de embaucar al mismísimo Júpiter (c. 200, vv. 65-70) ${ }^{59}$. Por su parte, Constancia reconocerá en el verso

${ }^{56}$ Desde un punto de vista semiótico, el conflicto entre las formas de vida apolíneas y dionisíacas fue muy fructífero desde la Antigüedad en adelante y es fácilmente detectable también en las religiones monoteístas, sobre todo si pensamos en la polaridad cristiana entre un vida pecaminosa y desenfrenada $v s$. una vida recta y esforzada. Para el caso de la mujer, esta polaridad se representa de manera obvia en los prototipos "mujer mala" / "mujer buena" (véase de nuevo el caso del Liber decem capitulorum), que no dejan de ser una extensión de las actitudes contrarias representadas por Eva y María. Un breve pero claro resumen del pensamiento aristotélico y platónico en torno a la mujer se encuentra en Murray 1995, pp. 3-4, quien nos demuestra que aunque para Platón la mujer era moralmente igual al hombre, su cuerpo era más débil y a través de esa debilidad se legitimaba su posición social inferior. Lo que hará Aristóteles es acentuar esta jerarquía y, al considerar a la mujer una versión imperfecta del hombre, su subordinación a este es vista como natural, línea que seguirá el cristianismo (d'Alverny 1977, esp. p. 107).

Para un estudio sobre lo que ha implicado en la historia cultural de Occidente (y en concreto, en la historia del feminismo) el dualismo filosófico cuerpo / mente, recomiendo el capítulo "Refiguring Bodies" de Grosz 1994.

${ }^{57}$ De paradiso 11, 50-51 (citado en d'Alverny 1977, p. 109, n. 26).

${ }^{58}$ Para un estudio detallado sobre la igualdad espiritual de hombres y mujeres véase McLaughlin 1974; para las citas véanse, respectivamente, Murray 1995, p. 5 y Grosz 1994, p. 13. Desde una postura opuesta a la de Grosz parece escribir Bynum cuando intenta desmontar el cliché, así llamado por ella (Bynum 1995, p. 6, n. 19), según el cual la tradición occidental ha sido marcada por un dualismo teórico-práctico para, al final, acabar apoyando sus argumentos en la misma confrontación de las categorías binarias cuerpo / espíritu que intenta superar. Para una revisión holística del llamado "giro del cuerpo" en los estudios culturales véase Cooter 2010.

${ }^{59}$ De todos modos, es muy importante la matización que hace Baudri más adelante, con la que consigue resemantizar su elogio a la belleza de Constancia y convertirlo en adecuado para 
21 de su carta que Baudri es un talentoso vates, y seguirá alabando su elocuencia y sabiduría (la cual comparará con la de Catón, Cicerón, Aristóteles y Homero) hasta el verso 50, a partir del cual utilizará 6 versos más para elogiar también su belleza, descrita de manera general y no específica como hacía Baudri. Esta descompensación en las descripciones de uno y otra sería acorde, pues, a las definiciones de ambos sexos para la época y afectaría también al tópico de la castidad presente en este intercambio. Lo cierto es que aunque en realidad virginidad, celibato y castidad sean condiciones que se presuponen a ambos personajes debido a sus vidas reales religiosas, en estas cartas asistimos también a una descompensación referencial de dichos presupuestos según cuál sea la voz poética que emite el mensaje, ligada por otro lado a dos diferentes roles muy marcados: el del hombre como maestro, figura de autoridad que conduce a la virgo hacia una vida recta, y el de la mujer como alumna, imagen de obediencia, que acepta las lecciones de quien sabe más que ella.

Esto implica que en la misiva de Baudri haya más preocupación por el mantenimiento de la virginidad de Constancia que al revés. Se puede apreciar cómo Baudri va guiando la correcta lectura de su carta casi desde el inicio de la misma, desmontando cualquier duda que Constancia (u otros) pudiesen tener acerca de la pureza de sus sentimientos: créeme, quiero que creas, y que quienes lean esto también crean: / un amor impuro nunca me ha conducido hacia ti (c. 200, vv. 37-38) ${ }^{60}$. En su condición de maestro, le indica a Constancia que lo que él desea es que en ella permanezca la virginidad como compañera y que, pese a que el mensaje del poema pueda ser ambiguo, es importante que ella entienda que no pretende de ningún modo que su castidad se vea perjudicada (c. 200, vv. 39-40). Jura y perjura que no quiere unirse a ella como esposo y la impele a firmar un pacto de amistad con el que sus

el cristianismo: "Por eso, precisamente, describo tu físico en el poema / para que tu apariencia externa dé cuenta de tu carácter interno" (c. 200, vv. 85-86).

${ }^{60}$ En estos versos, Baudri está reconociendo que su carta va a ser leída por más personas que Constancia. Constable ya nos indicaba al tratar de definir las características de la literatura epistolar en la Edad Media que "it is doubtful wheter there were any private letters in the modern sense of the term (...) medieval letters were often intended to be read by more than one person even at the time they were written", Constable 1976, p. 11.

Por otro lado, el hecho de que Baudri sea insistente a la hora de pautar cómo han de entenderse las ambiguas referencias presentes en su poema y de contextualizar su erotismo en el marco de la ficción y la jocosidad, nos está dando una pista a nosotros, lectores que investigamos el pasado, para que reflexionemos sobre la necesidad que en el XII habrían de tener de una hermenéutica del amor. Es importante destacar que hacia finales del mismo siglo tenemos a otro hombre de la Iglesia, Andreas Capellanus, escribiendo De amore, un tratado compuesto por tres libros; en los dos primeros explica cómo amar, en el último en cambio realiza un ataque contra el amor. 
corazones se junten mientras sus cuerpos permanecen separados ${ }^{61}$, lo que además de estar recalcando de nuevo la necesidad de entender el amor que le profesa despojado de toda carnalidad, está asimismo enfatizando la propia condición de la literatura epistolar en la Edad Media. Si la carta en esta época se entendía frecuentemente como un discurso entre dos personas ausentes (sermo absentis ad absentem), el elogio que el Patriarca Nicolás I de Constantinopla había hecho de la carta como una conversación espiritual de aquellos separados en cuerpo, para él más digna de alabanza que una conversación real, haría prosperar entre los hombres de la Iglesia un tipo de imagen concreta de este género literario, muy en la línea de estos versos baudrinianos ${ }^{62}$. Al intentar comprender por qué en la literatura religiosa medieval the best friend is nonetheless an absent one, sobre todo cuando en época clásica la presencia física del amigo se había definido como condición indispensable de la amistad (como muestra por ejemplo la concepción aristotélica sobre la misma), Robert McDonie concluye que esta habría sido una useful fiction en tanto que absent friends allow one to examine oneself by examining one's potential for friendship -the self-awareness, love, and benevolence that are required for all friendship ${ }^{63}$. Esta idea parece encajar muy bien con algunos de los principios básicos del cristianismo y, qué duda cabe, nos ayuda a entender mejor cuál sería el imaginario cultural en el que se podrían contextualizar estas amistades de cuerpos ausentes, pero aun así amistades pasionales y vigorosas, de las que nos hablan los autores medievales.

$\mathrm{Si}$ aceptamos que pensar en el otro nos ayuda a reflexionar sobre nuestro propio yo como un punto de partida epistemológico válido, también parece lógico admitir que desde una perspectiva genérica la carta se revelaría así un medio propicio con el que materializar el flujo de pensamiento que el otro motiva (y al que nos dirigimos durante el propio acto de escritura, aunque luego el envío de la carta pueda hacerse efectivo o no). En ese sentido, Verducci reconocía la potencialidad de la escritura epistolar para favorecer un tipo de autorrepresentación reveladora que en cambio the act of speech, coupled with the presence of a listener, would naturally inhibit ${ }^{64}$. Por otro lado, si bien es cierto que las cartas que me ocupan contienen poemas y que la poesía es un género que favorece también la autoexploración de uno mismo, no se debe olvidar que estamos ante poesía elegíaca, la cual en un sentido amplio

\footnotetext{
${ }^{61}$ c. 200, vv. 42-45: "Juro, por todo lo que existe: no quiero ser tu hombre: / no quiero ser tu hombre ni que tú seas mi mujer, / nuestras bocas y nuestros corazones fortalezcan la amistad, / juntados los corazones, queden sin embargo separados nuestros cuerpos".

${ }^{62}$ Constable 1976, p. 13.

${ }^{63}$ McDonie 2010, p. 10 y 8.

${ }^{64}$ Verducci 1985, p. 29.
} 
generically depict intermittently oppositional relations between its male and female characters ${ }^{65}$.

Con todo esto en mente, querría volver ahora a la imagen de Constancia venciendo, gracias a la escritura, su pudor ${ }^{66}$. Amparada en la expresión más libre y libertadora que le proporciona la escritura, Constancia le llega incluso a recriminar a Baudri que no vaya a visitarla, él que podría acudir a verla cuando quisiera dado que tiene mucho poder $^{67}$ :

Iría si pudiese, habría ido si hubiese podido, pero mi camino lo interrumpe mi cruel madrastra.

Pero tú, que eres señor, no tienes ningún guardián, tú a quien, porque tienes mucho poder, mi propia madrastra teme, llega con paso apresurado y ven a verme; tienes suficientes recursos y amigos. (c. 201, vv. 157-162).

En las siguientes estrofas le da ejemplos de las excusas que él fácilmente podría poner para ir a visitarla, pero inmediatamente se arrepiente de la osadía de decirle qué debe hacer, demostrando que ciertas dinámicas subyacentes de autoridad y poder están cruzando la relación que ambos mantienen:

Muchas ocasiones se producen para que vengas:

"el obispo, con quien tengo una charla, permanece en la ciudad, el clero me reclama, abades, este o aquel,

un asunto pendiente me trae hasta el conde..." ¿Estoy loca, a quién enseño? Tú eres quien me debe enseñar a mí.

Si te falta un motivo, rechazas venir.

No te preocupas por mí si no has venido a mí, ni siquiera un templado amor mueve tus vísceras. (c. 201, vv. 163-170).

La fórmula ¿estoy loca, a quién enseño? parece que más que una pregunta retórica y banal estaría verbalizando una opinión general de la época, a la luz de la afirmación que Ivo de Chartres recogía también en Decretum sobre la no autoridad de las mujeres:

Es bien sabido que la mujer está sometida a la dominación del hombre y que no tiene ninguna autoridad, con lo que no puede enseñar, ni testificar, ni dar fe, ni juzgar, cuanto más no puede mandar ${ }^{68}$.

\footnotetext{
${ }^{65}$ James 2003, p. 7.

${ }^{66}$ Véase de nuevo el c. 201, vv. 105-6.

${ }^{67}$ Véase la nota 7.

${ }^{68}$ Decretum, PL 161, 601, 85.
} 
Es por eso que Constancia lamenta su locura, pues a pesar de ser la docta puella o mujer culta que, como el propio código elegíaco exige, can understand, appreciate and evaluate the literary strategies of a given poem ${ }^{69}$, ha sobrepasado los límites que culturalmente definen su género al enseñarle a Baudri qué tretas podría acometer para verla.

Constancia, que entiende la tensión entre el mundo masculino y el femenino que la literatura de la época verbaliza, está sintetizando en la última estrofa presentada la dicotomía cuerpo / mente que he venido describiendo como negociación en la construcción de dinámicas de identidad y de género para aquel período. Primero porque se retracta y se disculpa de sus exigencias al definirse como demens, que literalmente significa "que está fuera de su mente". Segundo porque el reproche final que le hace a Baudri (v. 170: tu templado amor no mueve tus entrañas) nos pide ser leído contra el telón de fondo de otros versos suyos del inicio, en los que demostraba ser consciente de los efectos del amor en su propio cuerpo: En sueños insomne estaba, porque tu carta / sobre mi regazo ciertamente me quemaba las entrañas (vv. 17-18). La respuesta a una carta que a ella le había hecho arder en deseos de ver al amante es muy probable que no tenga el mismo efecto en él, cuyo amor es más medido y no se localiza en las entrañas (viscera), como el de ella. Sin querer entrar en el debate sobre las emociones y su componente somático (¿son los cambios en el cuerpo los que causan las emociones, o son por el contrario un reflejo de sus efectos? $)^{70}$, no se puede obviar por más tiempo que la expresión afectiva en la carta de Constancia lleva parejas referencias al cuerpo y sus gestos de una manera más frecuente y más consciente que en el caso de Baudri. Los propios versos inaugurales son un muy buen ejemplo: He leído atentamente esta carta siguiendo con fervor su huella / y he tocado tu poema con mi mano desnuda (c. 201, vv. 1-2). Constancia está cumpliendo, obediente, la petición con la que Baudri abría su misiva:

Lee atentamente el pergamino y, una vez leído, enróllalo con cuidado, que no perjudique mi fama una lengua maliciosa.

Lee atentamente, cautelosa y a solas, mis versos, lee: lo que esto sea, una mano amiga lo ha escrito ${ }^{71}$;

${ }^{69}$ James 2003, p. 7. No en vano Constancia entiende las referencias ovidianas de la carta de Baudri y adopta el rol de una de sus heroínas escribiendo además un poema con el mismo número de versos que el de él, como ya he mencionado.

${ }^{70}$ Véase Prinz 2004.

${ }^{71}$ El eco de Heroidas IV, 3 es claro en mi opinión. Fredra le pedía a Hipólito: "Lee atentamente, lo que esto sea - ¿qué daño puede hacer leer una carta?-". Baudri mantiene una estructura semejante y un tono también tranquilizador: la carta no puede dañar a Constancia, en este caso porque la ha escrito una mano amiga. Aunque en ambas misivas el contenido pueda no ser apropiado (Fedra le escribe una carta de amor a su hijastro, Baudri a su "hermana"), es la inocencia 
una mano amiga lo ha escrito y también un amigo lo ha dictado, el mismo que ha escrito el poema lo ha a su vez elaborado.

(c. 200, vv. 1-6).

Usando el mismo verbo que él había empleado también en posición inicial (perlegere o, lo que es lo mismo, leer atentamente), Constancia le confirma en su respuesta que ha leído su carta tal y como él le pedía. Sin embargo, habrá conseguido ir un paso más lejos que él: la mano amiga que en la epístola de Baudri es la que ha compuesto el poema, se actualiza en la misiva de ella como la mano desnuda que lo ha recorrido. El proceso de lectura en Constancia es un proceso físico, que implica otros sentidos (y otras sensaciones) a mayores de la vista, y que tiene consecuencias directas en su cuerpo ${ }^{72}$. Es asî que Constancia continúa explicando a Baudri que ha desenrollado el pergamino que contenía su carta llena de alegría dos, tres, hasta cuatro veces (c. 201, v. 3) y que tan gratas le fueron sus palabras que el día se consumía con ella leyéndolas una y otra vez (c. 201, vv. 5-6); solo la noche, molesta con tanto estudio, la obliga a dejarlo (c. 201, vv. 7-8). El pasaje que sigue merece una lectura más detallada:

Puse sobre mi regazo la carta y la coloqué debajo del pecho izquierdo para que estuviese más cerca del corazón, como dicen.

Si pudiese confiar tus páginas a mi corazón, confiaría cada una a mi corazón, no a mi regazo.

Finalmente, al profundo sueño nocturno abandoné mis miembros cansados, pero un amor agitado no conoce la noche.

¿Qué no esperaba? ¿Qué no me estaba permitido esperar?

El libro traía la esperanza, la noche el ocio. (c. 201, vv. 9-16).

Este fragmento, en el que nos adentramos en la vida íntima de la monja en su cuarto (a place to which outsiders do not normally have ac$\operatorname{ces}^{73}$ ), está marcado por la gestualidad que acompaña al acto de lectura y que está efectivamente afectando a unas partes del cuerpo concretas. Constancia ha colocado sobre su regazo la carta de Baudri; gremium es, en el sentido que el TLL recoge como propio, la parte del cuerpo entre las rodillas y la parte inferior del vientre cuando una persona está sentada. Se trata de la misma zona sobre la que la heroína Cánace había dejado la carta que había

del medio (la epístola, la mano amiga que la escribe) la que contrarresta sus efectos. Que el contenido de la carta baudriniana puede ser problemático lo deja claro el poeta ya en el segundo verso, al preocuparse por que su obra se vea perjudicada por las malas lenguas.

${ }^{72}$ Para un estudio general sobre las diferentes conexiones emocionales y somáticas que se pueden dar entre los textos medievales y sus experiencias de lectura véase Amsler 2001.

${ }^{73}$ Kong 2010, p. 45. 
escrito a su amante y hermano en el momento antes de suicidarse (Heroidas XI, vv. 3-4). Es un área que está cerca del estómago, y por ende de las vísceras, es decir, de los órganos internos del cuerpo, especialmente dentro del estómago que, en su sentido figurado, implican también el emplazamiento de una emoción, sentimiento o pensamiento ${ }^{74}$. Es la parte de su cuerpo en la que, recordemos, Constancia sitúa la quemazón que le produce la carta, o lo que es lo mismo la pasión, y que contrapone a la templanza que no mueve las vísceras de su amado. Isidoro, en sus Etimologías, localizaba en el hígado (iecur) el emplazamiento del calor que luego subiría al cerebro y que desde ahí se expandiría a los ojos y a otros sentidos y miembros ${ }^{75}$. En el hígado se sitúa, según él, el placer (voluptas) y el deseo (concupiscentia). Cuando Constancia le confiesa a Baudri que si pudiese no confiaría sus páginas a su regazo, donde las vísceras se le calientan y le insuflan una pasión que no la deja dormir, sino a su corazón, fuente de las preocupaciones y del conocimiento ${ }^{76}$, ¿está acaso hablando de una incapacidad para racionalizar sus deseos? ¿Está esta limitación relacionada con su propia naturaleza, con su cuerpo de mujer? La observación de Constancia se encuentra en diálogo directo con los versos 49-50 de Baudri, donde este reconocía no haber sentido por ella ni un amor lascivo ni insolente que, por su causa, le hubiesen destrozado el corazón o el hígado. Es decir, a Baudri ni se le ha nublado la razón, ni le han ardido las entrañas de pasión. Su amor por Constancia no ocasiona respuestas en su cuerpo, mientras que ella en cambio nos muestra una visión agitada de sus afectos y de su cuerpo ${ }^{77}$. A su vez, Constancia mantiene una esperanza que se confía a la noche y a las gratas palabras que le ha escrito el amado, una esperanza que pone en entredicho los límites del decoro y la decencia: “¿qué no me estaba permitido esperar?", resuena en la alcoba de la monja.

En definitiva, se podría afirmar a la luz de estos textos que el cuerpo puede ser efectivamente una frontera pero también un camino, una vía de escape. Constancia ha sabido usar la potencialidad de sus deseos para abrirse paso en la tensión dialéctica que mantiene con Baudri y en la que, de fondo, se están cuestionando los límites del código (elegíaco, epistolar, cristiano). Así, la monja complacerá la exigencia del maestro de vivir castamente, aunque reconociendo que esta era una decisión que ya había tomado ella antes de que él se lo ordenase. Por otro lado, matizará el erotismo de su carta describien-

\footnotetext{
${ }^{74}$ Así lo recoge el DMLBS en su entrada para "viscus": "internal organ of body (esp. within the abdomen, usu. pl., also transf. or fig.)". Otra de sus acepciones es: "innermost parts as seat of emotion, feeling, or though".

${ }^{75}$ Etimologías, 11, 1, 125.

${ }^{76}$ Etimologías, 11, 1, 118.

${ }^{77}$ Así lo apunta también Kong 2010, p. 46.
} 
do el amor que siente por su "hermano" como reflejo natural del que profesa a Dios, al que llama esposo ${ }^{78}$ :

Tú mandas, querido mío, tú ordenas, digo, que consagre mi obra a leyes castas.

La consagraré, si tú lo ordenas, así yo misma lo prefiero, pues de este modo he dispuesto hasta ahora mis propios días.

He sido casta, soy casta, quiero vivir casta;

¡ay, si pudiese vivir como esposa de Dios!

Por eso, yo no detesto tu amor:

la esposa de Dios debe amar a sus siervos.

Tú eres siervo de mi esposo, tú eres hermano y compañero de herencia,

tú también, tú eres digno del amor de mi esposo.

Una esposa debe venerar a los amigos de su esposo: así yo te venero, te amo atentamente.

(c. 201, vv. 109-120).

\section{CONCLUSIONES}

El análisis del intercambio epistolar entre Baudri de Bourgueil y Constancia de Le Ronceray ha puesto de relieve, según espero, una serie de ambigüedades y tensiones que atañen tanto al nivel del contenido como al del discurso. Al amparo de un juego recurrente entre ficción y realidad, por un lado, y entre paganismo (especialmente a través del uso de Ovidio) y cristianismo por otro, ha quedado demostrado que es posible amar en tiempos monásticos de una manera erótica a la vez que casta. El uso del código elegíaco como canal expresivo de este amor que nace en el cuerpo pero que sabe cómo superarlo en su camino hacia Dios posibilita la propia subversión del código, quedando incluso por momentos alteradas las representaciones tradicionales de género.

Una hipótesis coherente con la que entender el sentido de estos textos nos la proporciona el propio contexto histórico en el que ven la luz, cuando tanto el amancebamiento como el matrimonio clerical estaban siendo perseguidos y expuestos a escarnio público. El sínodo celebrado en Letrán en 1059 habría fijado unas nuevas normas de comportamiento social, pero ya se vio al inicio de este estudio que los cambios drásticos en la manera de vivir el mundo y hacerlo nuestro conllevan períodos de adaptación, confrontación e incluso incumplimiento. Así, si en época de Baudri y Constancia era más normal infringir los mandatos del sínodo que acatarlos, parece plausible entender la literatura presentada como prueba de la importancia que el sexo y el matrimonio

\footnotetext{
${ }^{78}$ Baudri ya había dicho que Constancia era "la esposa de su Señor". Véase de nuevo la nota 36 .
} 
tenían todavía cuando vivieron nuestros protagonistas, asunto este que entraría en conflicto con la sanción social que empezaba a exigir de los hombres de la Iglesia el olvido de los deseos carnales y la reconducción del amor pasional hacia Dios. Las estrategias de representación que se han visto enunciadas en el intercambio epistolar entre Baudri y Constancia pueden caber, y de hecho caben, en la tensión y ambigüiedad propia de un momento histórico en el que el amor carnal entre hombres y mujeres de la vida religiosa tiene que reconfigurarse como amor entre hermanos que sirven a un mismo padre. La metáfora de la esposa de Dios que vimos encarnada en Constancia ayudaría, según creo, en la inserción de la mujer dentro de un discurso nuevo de amor casto y virtuoso en el que el compromiso del matrimonio, con toda la sensualidad que este pueda aún suscitar, solo debe darse ya con Dios. Dentro de este programa, la mujer culta también tiene cabida e incluso se le otorga una función. Así, reconocerla como hermana de los siervos de Dios es concederle la honra (y la obligación) de predicar con el ejemplo cristiano de una vida casta y esforzada, como ya se vio. Reconocerla, a su vez, como esposa de Dios, supondría considerarla capaz de otorgar virtud a los hombres, suavizando los corazones de aquellos que se hayan alejado o se quieran alejar del rebaño.

\section{BIBLIOGRAFÍA CITADA}

Amsler, Mark (2001), Affective Literacy: Gestures of Reading in the Later Middle Ages, "Essays in Medieval Studies" 18, pp. 83-110.

Avril, Joseph (1983), Les fondations, l'organisation et l'evolution des établissements de moniales dans le diocèse d'Angers ( $d u X I^{e}$ au XIII ${ }^{e}$ siècle), en Parise, Michel (ed.), Les Religieuses en France au XIIIe siècle, Nancy, Presses Universitaires de Nancy, pp. 27-67.

Barchiesi, Alessandro (1994), Il Poeta e Il Principe. Ovidio e il discorso augusteo, Roma, Laterza.

Beach, Alison (2002), Voices from a Distant Land: Fragments of a TwelfthCentury Nuns' Letter Collection, "Speculum" 77, pp. 34-54.

Beach, Alison (2004), Women as Scribes: Book Production and Monastic Reform in Twelfth-Century Bavaria, Cambridge, Cambridge University Press.

Bond, Gerald (1986), Iocus amoris: the Poetry of Baudri of Bourgueil and the Formation of the Ovidian Subculture, "Traditio" 42, pp. 143-193.

Bond, Gerald (1987), Composing Yourself: Ovid's Heroides, Baudri of Bourgueil and the Problem of Persona, "Medievalia" 13, pp. 83-117.

Brinkmann, Hennig (1971), Entstehungsgeschichte des Minnesangs, Darmstadt, Wissenschaftliche Buchgesellschaft. 
Brower, Susannah G. (2011), Gender, Power, and Persona in the Poetry of Baudri of Bourgueil, Toronto, Center for Medieval Studies, University of Toronto (tesis doctoral).

Bulst, Walther (1950), Liebesbriefgedichte Marbods, en Bischoff, Bernhard; Brechter, Suso (eds.), Liber Floridus: Mittellateinische Studien Paul Lehmann, zum 65 Geburtstaag am 13. Juli 1949, St. Ottilien, Eos Verlag der Erzabtei, pp. 287-301.

Butler, Judith (1998), Actos performativos y constitución del género: un ensayo sobre fenomenología y teoría feminista [trad. Marie Lourties], "Debate Feminista" 18, pp. 296-314.

Bynum, Caroline (1995), Why All the Fuss About the Body? A Medievalist's Perspective, "Critical Inquiry" 22/1, pp. 1-33.

Champollion, Jacques-Joseph (1838), Hilarii versus et ludi, París, Lutetiae Parisiorum.

Constable, Giles (1976), Letters and Letter-Collections, en Genicot, Léopold (dir.), Typologie des Sources du Moyen Age Occidental, fasc. 17, Turnhout, Brepols.

Cooter, Roger (2010), The Turn of the Body: History and the Politics of the Corporeal, "Arbor. Ciencia, Pensamiento y Cultura” 743,pp. 393-405. d'Alverny, Marie-Thérèse (1977), Comment les théologiens et les philosophes voient la femme, "Cahiers de civilisation médiévale" 78-79 (20e année), pp. 105-129.

Farmer, Sharon (1986), Persuasive Voices: Clerical Images of Medieval Wives, "Speculum" 61/3, pp. 517-543.

Farmer, Sharon (1987), Softening the Hearts of Men: Women, Embodiment, and Persuasion in the Thirteenth Century, en Cooey, Paula; Farmer, Sharon; Ellen, Mary (eds.), Embodied Love: Sensuality and Relationship as Feminist Values, San Francisco, Harper \& Row, pp. 115-133.

González García, Alberto (2013), El Papa Urbano II y el origen de la Garcineida, "Anuario de Estudios Medievales" 43/2, pp. 609-647.

Grosz, Elizabeth (1994), Volatile Bodies: Toward a Corporeal Feminism, Bloomington, Indiana University Press.

Guillot, Olivier (1972), Le comte d'Anjou et son entourage au XI siècle, vols. I-II, París, Picard.

Hamburguer, Jeffrey; Marti, Susan (eds.) (2008), Crown and Veil.Female Monasticism from the Fifth to the Fifteenth Centuries, Columbia, Columbia University Press.

Harvey, Elizabeth (1995), Ventriloquized Voices: Feminist Theory and English Renaissance Texts, Londres, Routledge.

Huneycutt, Lois (1996), Proclaiming her dignitiy abroad: The Literary and Artistic Network of Matilda of Scotland, Queen of England 1100- 
1118, en McCash, June (ed.), The Cultural Patronage of Medieval Women, Georgia, University of Georgia Press, pp. 155-174.

James, Sharon (2003), Learned Girls and Male Persuasion: Gender and Reading in Roman Love Elegy, Berkeley, University of California Press.

Kong, Katherine (2010), Lettering the Self in Medieval and Early Modern France, Cambridge, D.S. Brewer.

Leclercq, Jean (1949), Yves de Chartres: Correspondence, París, Les Belles Lettres.

LoPrete, Kimberly (1992), Adela of Blois and Ivo of Chartres: Piety, Politics and Peace in the Diocese of Chartres, "Anglo-Norman Studies" 14, pp. 131-152.

LoPrete, Kimberly (2007), Adela of Blois, Countess and Lord (c. 1067-1137), Dublín, Four Courts Press.

Marchegay, Paul (1854), Archives d'Anjou: recueil de documents et mémoires inédites sur cette province, vol. 3, Angers, Cosnier et Lachèse.

Marchegay, Paul (1876), Charte en vers de l'an 1121, composée par Hilaire, disciple d'Abailard et chanoine du Ronceray d'Angers, "Bibilothèque de l'École de Chartes" 37, pp. 245-252.

McDonie, Robert (2010), Absent Friends: Fictions of Friendship in Early Medieval Latin and English Religious Literature, California, University of California (tesis doctoral).

McLaughlin, Eleanor (1974), Equality of Souls, Inequality of Sexes: Women in Medieval Theology, en Radford, Rosemary (ed.), Religion and Sexism: Images of Women in the Jewish and Christian Traditions, Nueva York, Simon and Schuster, pp. 213-266.

Migne, Jacques (1854), Patrologia Latina, vol. 161, edición digital a través de http://patristica.net/latina/ [consulta: 12/01/2018].

Migne, Jacques (1855), Patrologia Latina, vol. 166, edición digital a través de http://patristica.net/latina/ [consulta: 12/01/2018].

Munk Olsen, Birger (1989), Les bibliothèques bénédictines et les bibliothèques de cathédrales: les mutations des XI et XII ${ }^{e}$ siècles, en Vernet, André (dir.), Histoire des bibliothèques françaises, París, Éditions du Cercle de la Librairie - Promodis, vol. 1, pp. 31-43.

Murray, Jacqueline (1995), Thinking about Gender: the Diversity of Medieval Perspectives, en Carpenter, Jennifer; MacLean, Sally-Beth (eds.), Power of the Weak: Studies on Medieval Women, Urbana, University of Illinois Press, pp. 1-27.

Pasquier, Henri (1878), Un Poète Latin du XI siècle. Baudri, Abbé de Bourgueil, Archevêque de Dol 1046-1130, d'après des documents inédits, París, E. Thorin - Angers, Lachese et Dolbeau. 
Peteul, Julie (2005), Aborder l'histoire d'une communauté de femmes aux XI et XII siècles dans l'ouest de la France. Etude des cartulaires de l'abbaye du Ronceray d'Angers, Rennes, Université Rennes 2 (Mémoire de Master 2, Bibliothèque du CRHISCO).

Prinz, Jesse (2004), Gut Reactions: a Perceptual Theory of Emotion, Nueva York, Oxford University Press.

Salies, Alexandre de (1874), Histoire de Foulques-Nerra, Comte d'Anjou. D'après les chartes contemporaines et les anciennes chroniques, París, J.-B. Dumoulin.

Scott, Joan W. (1999), Gender as a Useful Category of Historical Analysis, en Parker, Richard; Aggleton, Peter (eds.), Culture, Society and Sexuality: A Reader, Londres, UCL Press, pp. 57-75.

Tilliette, Jean Yves (1983), Notes sur le manuscript des poèmes de Baudri de Bourgueil (Vatican, Reg.Lat. 1351), "Scriptorium" 37, pp. 241-245.

Tilliette, Jean Yves (1992), Hermès amoureux, ou les métamorphoses de la Chimère. Réflexions sur les carmina 200 et 201 de Baudri de Bourgueil, "Mélangues de l'Ecole française de Rome. Moyen-Âge" 104/1, pp. 121-161.

Tilliette, Jean Yves (2002), Baudri de Bourgueil, Carmina, vol. II, París, Les Belles Lettres.

Tilliette, Jean Yves (2012), Baudri de Bourgueil, Carmina, vol. I (2. ${ }^{a}$ ed.), París, Les Belles Lettres.

Tuten, Belle (1997), Holy Litigants: the Nuns of Ronceray d'Angers and their Neighbors, 1028-1200, Atlanta, Faculty of the Graduate School, Emory University (tesis docotoral).

Tuten, Belle (2004), Who was Lady Constance of Angers? Nuns as Poets and Correspondents at the Monastery of Ronceray d'Angers in the Early Twelfth Century, "Medieval Perspectives" 19, pp. 255-268.

Tyler, Elizabeth (2017), England in Europe. English Royal Women and Literary Patronage c. 1000-c. 1150, Toronto, University of Toronto Press.

Verdon, Jean (1976), Les moniales dans la France de l'Ouest aux XI' et XII siècles. Étude d'histoire sociale "Cahiers de civilisation médiévale" 75 , pp. 247-264.

Verducci, Florence (1985), Ovid's Toyshop of the Heart: Epistulae Heroidum, Princeton, Princeton University Press.

Weston, Lisa (2013), Conceiving the Word(s): Habits of Literacy among Earlier Anglo-Saxon Monastic Women, en Blanton, Virginia; O’Mara, Veronica; Stoop, Patricia (eds.), Nun's Literacies in Medieval Europe: The Hull Dialogue, Turnhout, Brepols, pp. 149-167.

Fecha de recepción del artículo: febrero 2018

Fecha de aceptación y versión final: noviembre 2018 